\title{
La pintura rupestre esquemática en Murcia. Estado de la cuestión
}

\author{
Miguel Ángel Mateo Saura y José Antonio Bernal Monreal
}

\section{RESUMEN}

El continuo descubrimiento de yacimientos de arte rupestre de estilo esquemático en Murcia, ha reportado hasta la fecha un importante bagaje de información, que no siempre ha sido examinada con el rigor mínimo exigible ni bajo unos parámetros que le dieran uniformidad en el contexto del arte prehistórico regional.

Con este trabajo de síntesis pretendemos establecer unos puntos comunes de partida en el análisis de la pintura rupestre esquemática, para que, una vez superados los aspectos puramente estéticos, podamos avanzar en otras facetas del arte como es su contextualización cronológica y cultural y, por ende, el transfondo ideológico que lo sustenta.

\section{PALABRAS CLAVE}

Arte rupestre, pintura esquemática, Murcia.

\section{SUMMARY}

The ongoing discoveries of cave painting sites of the schematic style in Murcia so far has provided with an important bulk of information, which has not always been approached by following the adequate accuracy nor guidelines so as to give shape to it within the context of the local prehistoric art.

By this synthesizing piece of work, we intend to lay down some common starting points for the analysis of schematic cave painting. Once overcome the purely aesthetic aspects of art, we will aim to consider others, such as 
the chronological and cultural context and, consequently, the ideological background supporting it.

\section{KEY WORDS}

Cave painting, schematic painting, Murcia.

\section{RÉSUMÉ}

La découverte continuelle de gisements d'art rupestre de style schématique à Murcie a apporté, jusqu'à present, un important bagage d'information qui n'a pas toujours été examinée avec la rigueur exigible, ni sous des paramètres qui puissent lui donner une uniformité dans le contexte de l'art préhistorique régional.

Avec ce travail de synthèse, nous prétendons établir des points communs de départ dans l'analyse de la pintura rupestreschématique pour que, une fois dépassés les aspects purement esthétiques, nous puissons avancer sur d'autres côtes de l'art comme sa contextualisation chronologique et culturelle et, par conséquent, le fond idéologique qui le soutient.

\section{MOTS CLÉ}

Art rupestre, peinture schématique, Murcie.

\section{INTRODUCCIÓN}

Aún cuando las primeras referencias sobre pintura rupestre esquemática en Murcia son de fecha muy temprana y el número de yacimientos, hasta el momento descubiertos se acerca ya a la treintena, se echa en falta un estudio de conjunto que establezca las bases para posteriores análisis que profundicen en otros aspectos del arte más allá de los puramente estéticos.

Este vacío en la investigación ha motivado que el arte esquemático regional haya pasado inadvertido en los estudios realizados a un nivel más general o también que sus representaciones hayan sido incluidas, sin mayores consideraciones, en núcleos artísticos vecinos como puedan ser el 
almeriense de Vélez-Blanco o, más al Norte, los núcleos de la Sierra de Segura y Noroeste de Granada ${ }^{1}$.

Una excepción fue el trabajo de la Dra. Acosta ${ }^{2}$, pero dada la fecha en que éste se publicó la mayor parte de las estaciones murcianas aún estaban inéditas, con lo que la información en él recogida fue muy limitada.

Esta situación nos ha llevado a poner en marcha un proyecto de revisión del arte esquemático de la provincia, en especial el de aquellos conjuntos descubiertos hace años, empleando en ello las nuevas técnicas de estudio del arte rupestre en lo que refiere a aspectos como la elaboración de dibujos o el registro fotográfico, entre otros.

\section{MARCO FÍSICO}

El actual territorio murciano, enclavado en el cuadrante Sureste de la Península lbérica, se encuentra accidentado por numerosas sierras, llanuras y depresiones, dentro del ámbito tectosedimentario del Prebético, con una litología en la que predominan los materiales terciarios y cuaternarios.

Los afloramientos de calizas, areniscas y margas en el relieve posibili$\tan$ la existencia de numerosos abrigos y covachas, la mayor parte de ellos de dimensiones reducidas, cuyas paredes han sido escogidas para la realización de manifestaciones artísticas pertenecientes a distintos horizontes cronológicos y culturales, entre los que hallamos los ciclos paleolitico, naturalista-levantino y esquemático.

La vegetación espontánea se encuentra muy degradada debido a factores diversos, fundamentalmente la acción humana y el avance paulatino de la aridez por la falta de precipitaciones, siendo sólo en los macizos montañosos del Norte y Noroeste donde se conservan especies con porte arbóreo, básicamente pino, y con carácter excepcional, reductos de sabinas en el sector más noroccidental de la provincia. La mayor parte del territorio ocupado por el arte esquemático está cubierto por especies de monte bajo, de tomillares como el espliego o el romero, y herbazales como el manrubio o el varbasco, entre otros.

\footnotetext{
1 Soria lerma, M. y López Payer, M. G. «Aproximación al estudio del significado de la pintura rupestre postpaleolítica del Sureste peninsular", Ars Praehistorica, VII-VIII. Barcelona 1989, págs. 167-182.

2 Acosta Martínez, P. La pintura rupestre esquemática en España, Memorias del Seminario de Prehistoria y Arqueologla, 1, Universidad de Salamanca. Salamanca 1968.
} 


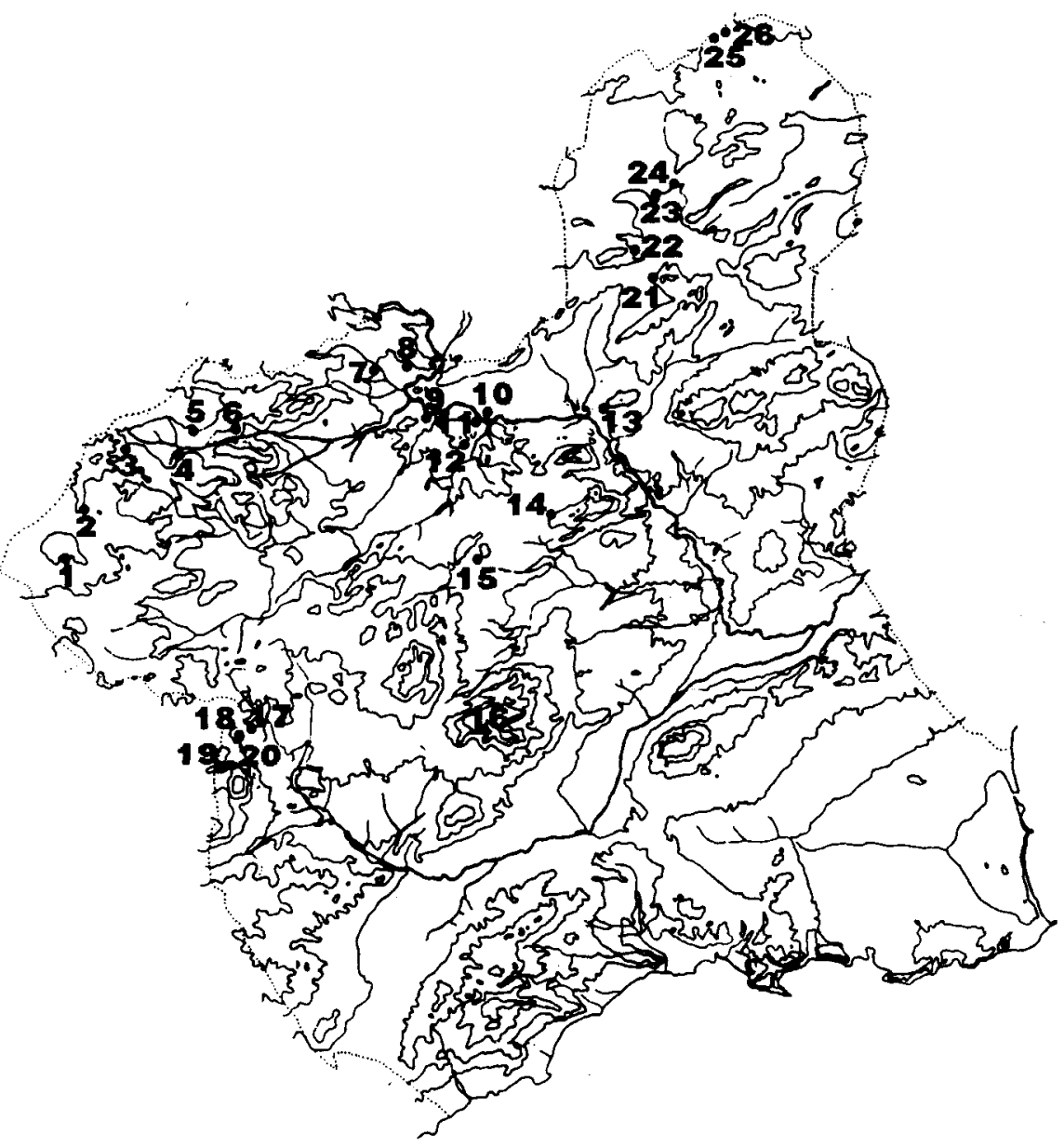

Figura 1. Localización de conjuntos con pintura esquemática en Murcia: 1. Abrigo de la Fuente (Moratalla); 2. Abrigo de Fuente Serrano (Moratalla); 3. Cañaica del Calar

(Moratalla); 4. Abrigos de Andragulla (Moratalla); 5. Abrigos de la Risca (Moratalla); 6. Abrigo de Hondares (Moratalla); 7. Cueva del Esquilo (Moratalla); 8. Cueva de los Cascarones (Moratalla); 9. Abrigos del Pozo (Calasparra); 10. Cueva de la Serreta (Cieza); 11. Abrigos de las Enredaderas (Cieza); 12. Cueva de los Pucheros (Cieza); 13. Abrigos de los Grajos (Cieza); 14. Abrigos del Cejo Cortado (Mula); 15. Abrigo del Milano (Mula); 16. Cueva de la Plata (Totana); 17. Abrigo de los Paradores (LorCa); 18. Cueva del Tío Labrador (LorCa);

19. Abrigo de los Gavilanes (LorCa); 20. Abrigo del Mojao (LorCa); 21. Abrigo de la Calesica (Jumilla); 22. Abrigo de Canto Blanco (Jumilla); 23. Cueva del Peliciego (Jumilla);

24. Abrigos del Buen Aire (Jumilla); 25. Cantos de Visera (Yecla); 26. Abrigo del Mediodía (Yecla). 
Conforme avanzamos hacia el Sur se observa una tendencia a un dominio árido, en el que la vegetación se caracteriza por matorrales y tomillares esteparios, con reducidos núcleos de masa forestal en los que domina el pino carrasco, entre ellos, las sierras de Carrascoy y de Espuña.

Los conjuntos de arte esquemático están desigualmente repartidos por el espacio geográfico regional, observándose una concentración de los mismos en el sector noroccidental de la provincia y en torno al curso medio del río Segura. Un segundo núcleo de yacimientos se ubica en el Altiplano de Yecla-Jumilla, en donde el relieve manifiesta ya características propias de la meseta, con amplias llanuras sólo quebradas por formaciones montañosas de escasa entidad y algunas ramblas. Un último grupo se localiza en el centro del territorio, en la llamada Cuenca de Mula, articulada por cursos menores de agua como son los ríos Pliego y Mula (fig. 1).

\section{HISTORIA DE LA INVESTIGACIÓN}

El descubrimiento del conjunto yeclano de Cantos de Visera en 1912 supuso la primera toma de contacto con el arte rupestre esquemático. No obstante, la atención que entonces se le prestó al mismo fue escasa ya que la convivencia en el mismo panel pintado de los motivos esquemáticos con otros del estilo levantino relegaba a aquellos a un segundo plano, influyendo en ello, sin duda, el que sus formas, más toscas, se minusvalorasen respecto a las naturalistas, mucho más llamativas desde un punto de vista estético.

De hecho, en los primeros estudios sobre el conjunto estas figuras abstractas se consideraron como una pervivencia tardía, ya neolítica, del arte rupestre de cronología paleolítica que representaban las otras figuras naturalistas de bóvidos y cérvidos ${ }^{3}$. Será el hallazgo del Abrigo del Mediodía, próximo a Cantos de Visera y con representaciones únicamente esquemáticas, el que propicie una mayor atención hacia este estilo.

También en estos años, la infatigable labor de estudio desarrollada por el abate H. Breuil ${ }^{4}$ en todo el Sureste permitirá la localización en 1933 del Abrigo de los Paradores y la Cueva del Tío Labrador, en Lorca, estre-

\footnotetext{
${ }^{3}$ BREUIL, H. y BuRKIT, M. aLes peintures rupestres d'Espagne. VI. Les abris peints du Monte Arabi prés Yecla (Murcia)", L'Anthropologie, XXVI. París 1915, págs. 313-328. Cabre AGullo, J. Arte rupestre en España, Comisión de Investigaciones Paleontológicas y Prehistóricas, 1, Madrid 1915. Zuazo Palacios, J. La Villa de Montealegre y su Cerro de los Santos. Madrid 1915.

4 Breuil, $H$. Les peintures rupestres schématiques de la Péninsule lbérique. IV. Sud-Est et Est de l'Espagne. Lagny 1935, págs. 35-36.
} 
chamente vinculados al importante núcleo de arte de la comarca almeriense de Vélez-Blanco.

Sin embargo, y a pesar de estos descubrimientos tempranos, se inicia a partir de entonces un vacío en los estudios del arte rupestre en Murcia, sólo salpicado por hallazgos ocasionales como los de la Cueva del Peliciego y La Calesica, en Jumilla. A este paréntesis en la investigación pondrá fin el descubrimiento a finales de la década de los 60 de los conjuntos del Barranco de los Grajos en Cieza y de la Cañaica del Calar en Moratalla.

Es también ahora cuando se publica la tesis de $P$. Acosta ${ }^{5}$, en la que se recoge todo el material conocido, englobándose en él a los conjuntos murcianos hasta ese momento descubiertos.

Estos hallazgos constituyeron un nuevo impulso al estudio del arte rupestre prehistórico en general. A su vez, la creación de colecciones municipales de arqueología y, sobre todo, la labor desarrollada por colectivos de arqueología de ámbito local, supusieron un mayor interés hacia el arte rupestre y la puesta en marcha de los primeros trabajos sistemáticos de prospección. En este contexto se inscribe el descubrimiento en 1978 de los Abrigos del Pozo, en Calasparra, y unos años más tarde, el Abrigo del Milano de Mula, localizado por el Colectivo de Arqueología de Bullas. También en ese tiempo, aunque de manera ocasional, se han descubierto los Abrigos de la Risca en Moratalla y los Abrigos de las Enredaderas en Cieza.

En estos últimos años, una mayor concienciación acerca de la importancia que los trabajos de prospección tienen en el estudio del arte rupestre, durante mucho tiempo abandonado a la suerte de esos hallazgos ocasionales, ha permitido la localización de numerosos conjuntos. En 1990, el colectivo de Amigos del Museo de Lorca descubre los Abrigos del Mojao y los Gavilanes, mientras que en la Comarca del Noroeste los trabajos de campo desarrollados por nosotros desde 1991 han dado como fruto el descubrimiento de varios grupos de pinturas, tanto naturalistas como esquemáticas, entre los que podemos destacar el Abrigo de la Fuente, la Cueva de los Cascarones o el Abrigo de Hondares, 'odos ellos en Moratalla.

En la actualidad, conocemos 26 estaciones con pintura rupestre esquemática en Murcia, estando ausentes, por ahora, las representaciones grabadas. Todos estos descubrimientos han generado una abundante literatura que se acerca al centenar de trabajos, y que han sido publicados tanto en revistas nacionales como internacionales.

\footnotetext{
5 acosta Maftínez, P. La pintura rupestre..., Op. cit. en la nota 2.
} 
No obstante, en la revisión de este material bibliográfico se aprecia una falta de correlación entre los trabajos publicados y los conjuntos descubiertos, de tal forma que mientras que algunos yacimientos cuentan con varios estudios, otros permanecen prácticamente inéditos, aún a pesar de conocer su existencia desde hace bastantes años ${ }^{6}$.

\section{ASPECTOS TÉCNICOS}

Los testimonios parietales esquemáticos en Murcia pertenecen todos al grupo de representaciones pintadas, si exceptuamos el núcleo de petroglifos del Altiplano, encuadrables de forma clara en otro horizonte

${ }^{6}$ Del material bibliográfico existente, reseñamos de cada conjunto aquellos trabajos que nos ofrecen una visión más amplia de cada uno de ellos. Del Abrigo de la Fuente, MATEO SAURA, M.A. "Las pinturas rupestres esquemáticas del Abrigo de la Fuente, Cañada de la Cruz (Moratalla, Murcia)", Caesaraugusta, 68. Zaragoza 1991, págs. 229-239. De la Cañaica del Calar, Beltrán Martínez, A. "Los Abrigos pintados de Cañaica del Calar y Fuente del Sabuco, El Sabinar (Murcia)", Monografías Arqueológicas, IX. Zaragoza 1972. MATEO SAUAA, M.A. "Figura en negro en el conjunto de la Cañaica del Calar (Moratalla, Murcia) y su aportación al estudio de los antropomorfos en el arte esquemático", I Congreso de Jóvenes Geógrafos e Historiadores. Sevilla, 1990. Sevilla 1995, págs. 477-484. De la Cueva del Esquilo, Mateo Saura, M.A. «Arte rupestre histórico de la Cueva del Esquilow, Revista de Arqueología, 170. Madrid 1995, págs. 9-13. De la Cueva de los Cascarones, Mateo saura, M.A.-Begnal Monreal, J.A.-Péfez Moñino, C. "Arte rupestre prehistórico en el Barranco de Charán (Moratalla, Murcia)", Revista de Arqueología, 158. Madrid 1994, págs. 6-9. Mateo Saura, M.A.-Beanal Monfeal, J.A. Los conjuntos pintados del Barranco de Charán (Moratalla, Murcia). Murcia 1995. Del Abrigo del Pozo, SAN NiCOLÁS DEL TORO, M. "Las pinturas rupestres esquemáticas del Abrigo del Pozo (Calasparra, Murcia)",Caesaraugusta, 61-62. Zaragoza 1985, págs. 95-118. Del Abrigo del Milano, Alonso TEJADA, A. et alii, "Abrigo de arte rupestre de "El Milano" (Mula)", Bienes de interés Cultural en Murcia, 1. Murcia 1987. Del Cejo Cortado, Montes Bernárdez, R.-SÁnchez Pravia, J. "Arte rupestre en Murcia. Nuevos hallazgos", Revista de Arqueología, 91. Madrid 1988, págs. 5-11. Del Abrigo de las Enredaderas, SALMERÓN JUAN, J. "Las pinturas rupestres esquemáticas de las Enredaderas (Los Almadenes) en Cieza, Murcia. Estudio preliminar", Bajo Aragón Prehistoria, VII-VIII. Zaragoza 1987, págs. 223-230. De la Cueva de la Serreta, MATEO SaURA, M.A. "Las pinturas rupestres de la Serreta, Cieza (Murcia)", Zéphyrus, XLIV-XLV. Salamanca 1992, págs. 241-250. MAteo SauRA, M.A. "Las pinturas rupestres de la Cueva de la Serreta, Cieza (Murcia)", Archivo de Prehistoria Levantina, XXI. Valencia 1994, págs. 33-46. De los Abrigos de los Grajos, Beltran MARTínez, A. "La Cueva de los Grajos y sus pinturas rupestres en Cieza (Murcia)", Monografias Arqueológicas, VI. Zaragoza 1969. De los Cantos de Visera, BREUIL, H.-BURKIT, M. "Les peintures rupestres...", Op. cit. en la nota 3. De La Calesica, Molina GARCiA, J. "Los cruciformes de la Calesica, Jumilla (Murcia)", Zéphyrus, XXI-XXII. Salamanca 1971, págs. 157-161. De los Abrigos del Buen Aire, GARCla DEL TORO, J.R. "Nuevos abrigos con pinturas rupestres en el Barranco del Buen Aire (Jumilla)", Anales de Prehistoria y Arqueologia, 1. Murcia 1985, págs. 105-110. De Canto Blanco, HeRnández Caraión, E. aNueva estación con pinturas rupestres en el término municipal de Jumilla (Murcia)", Revista de Arqueologia, 151, Madrid 1993, pág. 61. De la Cueva del Peliciego, Fernández AviLÉs, A. "Las pinturas rupestres de la Cueva del Peliciego, en término de Jumilla (Murcia)", Boletín de la Sociedad Española de Arte y Arqueología, IV. Valladolid 1940, págs 35-46. Fortea Perez, F.J. "Las pinturas rupestres de la Cueva del Peliciego o de los Morceguillos (Jumilla-Murcia)", Ampúrias, 36. Barcelona 1974, págs. 21-39. 
iconográfico distinto de lo que conocemos como arte rupestre esquemático.

Todas las pinturas se localizan en abrigos al aire libre, formados a partir de la disolución del carbonato cálcico en los terrenos calcáreos por la infiltración del agua de lluvia, de alto contenido en anhídrido carbónico.

Un aspecto a destacar es la proximidad de los conjuntos pintados a reservas de agua. En la mayor parte de los casos, los abrigos se localizan en las inmediaciones de cursos fluviales 0 , en su defecto, de cursos estacionales como son las ramblas. En ausencia de éstos, se ubican cerca de fuentes.

La orientación de los abrigos es variada, aunque se aprecia un predominio hacia unas orientaciones Sur y Sureste, y su altitud oscila entre los 250 m.s.n.m. de los Abrigos del Pozo de Calasparra, situados sobre el propio lecho del río Segura, y los 1600 m.s.n.m. del Abrigo de la Fuente de Moratalla, si bien la mayor parte de ellos se sitúan en un margen entre los 1000-1200 m.s.n.m.

El color predominante en las representaciones es el rojo, con diversas tonalidades que van desde unos tonos muy claros (Pantone $173 \mathrm{U})^{7}$ a otros bastante más oscuros (Pantone $209 \mathrm{U}$ ), mientras que la utilización del color negro ha sido menos frecuente. Otros colores, como el blanco, están aquí ausentes. Un estudio de los componentes del pigmento de varias muestras reveló la elaboración del color rojo a partir de bol rojo, una especie de silicato de aluminio ferruginoso, mientras que una muestra analizada de color negro mostró un origen orgánico y no mineral ${ }^{8}$.

Los únicos motivos pintados en negro son un humano de tipo golondrina en Cañaica del Calar, un cruciforme y un ramiforme en el Abrigo de los Gavilanes, unos trazos verticales en la Cueva de los Pucheros, un cérvido en los Abrigos del Buen Aire y un soliforme en los Abrigos de las Enredaderas.

Para la deposición del pigmento en el soporte se recurre a una técnica continua que permite una uniformidad en el trazo, dando lugar a tintas planas en algunos motivos, bien por su tipología o también por su tamaño. De este procedimiento se desprende el uso de algún tipo de instrumento que

\footnotetext{
7 Para la toma del color y con el fin de tener un registro objetivo del mismo, hemos utilizado comparativamente las Tablas de Color Pantone Color Formula Guide. 18 $8^{\mathrm{a}}$ Edición. 1986/87.

\& Montes Bernárdez, R.-Cabrera Garrido, J.A. «Estudio estratigráfico y componentes pictóricos del arte prehistórico de Murcia (Sureste de España)", Anales de Prehistoria y Arqueología, 7-8, Universidad de Murcia. Murcia 1992, págs. 69-74.
} 
actuase a modo de pincel, quizá elaborado a partir de pelo de animal. En unos pocos casos podemos intuir el empleo de los propios dedos de la mano, determinando con ellos trazos delgados como los observados en los serpentiformes o las barras, o también para marcar algunos puntiformes al modo de digitaciones.

Otros procedimientos son excepcionales. Así, en un motivo ancoriforme de la Cueva del Peliciego se recurre a un silueteado del perfil de la figura en un tono muy oscuro que resalta del relleno interior más claro.

En unos pocos conjuntos podemos documentar labores de repintado de motivos, realizadas sin duda, con la finalidad de renovar el significado de la figura originaria en el friso. En la Cañaica del Calar una representación de brazos en asa fue repintada en un segundo momento en una tonalidad más oscura, mientras que en un cuadrúpedo de los Abrigos del Pozo constatamos hasta tres tonalidades diferentes. Un rojo claro en la base, sobre el que se repinta en un color parduzco, y a su vez, un tercer repinte en la parte del hocico en un tono más claro.

Por otra parte y al margen de estos repintados que el ojo humano puede captar, el análisis de micromuestras desveló que en un humano en phi del Barranco de los Grajos hay hasta siete capas de pigmento ${ }^{9}$, reflejo de otros tantos momentos de revitalización del simbolismo de la figura.

Ese estudio de muestras permitió también documentar como a veces se recurre a una preparación previa del soporte antes de pintar los motivos. Por el momento sólo se ha constatado en el conjunto del Cejo Cortado, en el que por debajo de alguna de las figuras se aplicó antes una especie de preparado de tipo oleoso graso ${ }^{10}$, aunque puede que sea la propia escasez de estudios estratigráficos de pigmento la que nos haga considerar como excepcional esta práctica, tal vez más común de lo que en principio creemos.

Frente a los repintados, lo que se produce a veces es una superposición de motivos dentro del mismo panel pintado. Quizá se busca con ello anular el significado de un determinado pictograma en un momento dado y por circunstancias que para nosotros son desconocidas, y con la inclusión de nuevas figuras darle otra intencionalidad religioso-ritual al conjunto. En esta línea, en Cañaica del Calar un antropomorfo cubre parcialmente una

9 Montes Bernároez, R.-Cabrera Garrido, J.A. “Estudio estratigráfico...", Op. cit. en la nota 8. Pág. 72.

10 Montes Bernádeez, R.-Cabrera Garaido, J.A. "Estudio estratigráfico...», Op. cit. en la nota 8. Pág. 73. 
figura humana de brazos en asa, y en los Abrigos de las Enredaderas dos trazos se añaden en un segundo momento a unos restos de color para conformar una representación zoomorfa.

Algo distinto a los repintados y superposiciones lo vemos en una figura antropomorfa de la Cueva de la Serreta de Cieza (lám. I). Se trata de un humano de brazos en asa en el que se marcan detalles anatómicos poco comunes a este tipo de motivos como son las dos piernas, con sus respectivos pies, o la cabeza, perfectamente diferenciada y provista de un notable tocado de forma rectangular. Pero, al margen de todos estos rasgos, lo más llamativo de esta figura es que en todo su contorno muestra una serie de puntos, a modo de rayos, pintados en un color mucho más oscuro que el del resto de la figura. Examinada con detenimiento, no encontramos puntos de apoyo que nos lleven a pensar en repintados o añadidos posteriores, sino que, por contra, la conclusión a la que llegamos cuando estudiamos el conjunto es que desde un principio se representó así la figura, con esa especie de "bicromía»".

El tamaño de las figuras oscila entre los escasos $2 \mathrm{~cm}$ de algunos puntiformes y los $76,5 \mathrm{~cm}$ de un polilobulado de la Cueva de la Serreta, si bien la mayor parte de ellas se enmarcan entre los 5 y $30 \mathrm{~cm}$, lo que sitúa a las representaciones murcianas dentro de la tónica general del estilo esquemático.

Por otro lado y con carácter excepcional, vemos en ocasiones como el soporte físico desempeña un papel activo como elemento compositivo, precisando el significado último de alguno de los motivos pintados. Así, en el Abrigo de los Gavilanes, una pequeña oquedad formada por erosión de carácter alveolar ha sido escogida para pintar en su interior un motivo puntiforme.

Sin embargo, donde este aprovechamiento de los rasgos del soporte alcanza su máxima expresión en las estaciones murcianas es en el Abrigo de la Fuente. En él, las dos figuraciones de serpentiformes, interpretadas en su momento como la representación de cursos de agua ${ }^{12}$, se sitúan debajo de sendas oquedades en la pared del abrigo. Si tenemos en cuenta

11 Sobre las pinturas de la Cueva de la Serreta se han publicado varios trabajos desde su descubrimiento en 1973. Los más recientes son GARCIA DEL TORO, J.R. "Las pinturas rupestres de la Cueva-sima de la Serreta (Cieza-Murcia). Estudio preliminar", Anales de Prehistoria y Arqueología, 4, Universidad de Murcia, Murcia 1988, págs. 33-40. Mateo SaURA, M.A. «Las pinturas rupestres de La Serreta...", Op. cit. en la nota 6. MATEO SAURA, M.A. "Las pinturas rupestres de la Cueva...", Op. cit. en la nota 6.

12 Mateo Saura, M.A. “Las pinturas rupestres esquemáticas...", Op. cit. en la nota 6. Pág. 234 
que en el fondo de la cueva hay un hueco por el que hasta hace muy poco tiempo manaba un hilo continuo de agua, no resulta aventurado proponer que el artista, al pintar esas figuras debajo de esas oquedades, lo que buscaba era trasladar a un plano de representación la realidad física del abrigo. Aprovechó esos accidentes naturales del soporte para pintar debajo el agua por medio de trazos serpenteantes, mientras que los huecos cumplirían la misma función que el orificio más grande del fondo del abrigo (lám. II).

\section{ESTUDIO TIPOLÓGICO}

Aunque escasos en su número, en los conjuntos murcianos encontramos representados la mayor parte de motivos que conforman el repertorio iconográfico de la pintura esquemática, si bien con una distribución un tanto desigual entre éstos.

Para la exposición de esos motivos, y con el fin de mantener la unidad con otros trabajos publicados, seguimos la tipología establecida hace años por P. Acosta ${ }^{13}$ que, al margen de aquellas puntualizaciones de carácter local que se puedan realizar, es conocida y aceptada por todos.

ANTROPOMORFOS: entre las representaciones humanas documentamos la mayor parte de los tipos establecidos, desde los esquemas humanos más simples hasta aquellos otros dotados de un acusado grado de abstracción y para los que su identidad como tales representaciones humanas no deja de ser sino una hipótesis de trabajo.

La esquematización humana más simple es aquella formada por un trazo vertical que al llegar a la altura de la cintura se bifurca en dos para formar las piernas, mientras que otros trazos horizontales determinan los brazos. En ocasiones, un punto representa la cabeza, aunque ésta no siempre está presente (lám. III). Este esquema lo encontramos en Cañaica del Calar, Abrigos de Andragulla, Abrigos del Cejo Cortado, Cueva de la Serreta, Abrigo del Mojao, Abrigo de los Gavilanes, Abrigo de los Paradores, Cueva del Tío Labrador, Cantos de Visera y Abrigo del Mediodía.

En la mayor parte de los casos no es posible determinar el sexo de las representaciones, definiéndolas entonces en función del contexto en el que se inscriben. Del grupo de motivos humanos, tan sólo podemos proponer como femenina a una figura del conjunto muleño del Cejo Cortado, a tenor de la prenda con la que va vestida, semejante a una falda.

\footnotetext{
13 Acosta Martinez, P. La pintura rupestre..., Op. cit. en la nota 2.
} 


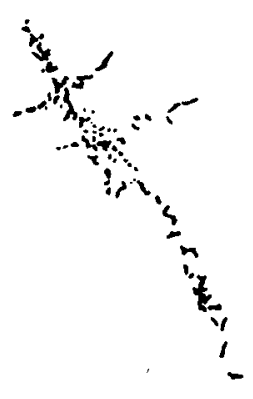

1

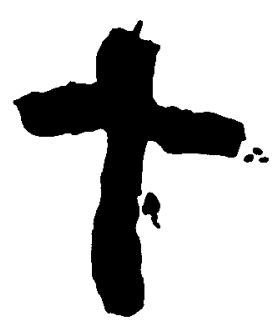

4

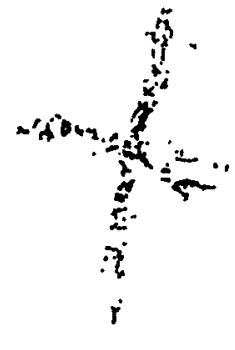

2

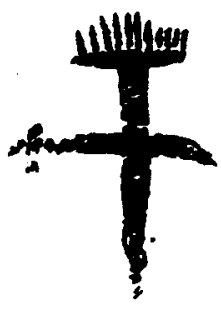

5

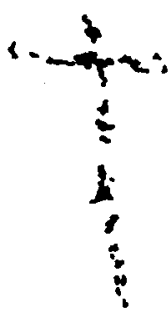

3

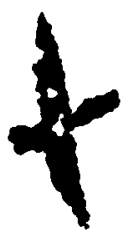

6

Figura 2. Tipo cruciforme: 1-2. Cueva de los Cascarones (Mateo-Bernal, 1995);

3. Abrigo de Hondares; 4. La Calesica (Molina, 1971); 5. Cantos de Visera (Cabré, 1915); 6. Abrigo de los Gavilanes.

Junto a este esquema humano simple, de los otros tipos propuestos como abstracciones humanas reconocemos en Murcia los siguientes:

Tipo cruciforme: en él hay una acusada simplificación en el trazo que conduce a una representación formada por dos líneas cruzadas en la que la vertical, por lo general la más larga, simboliza el cuerpo desde la cabeza a los pies, y la horizontal, las extremidades superiores extendidas (fig. 2). Este tipo se documenta en el Abrigo de Hondares, Cueva de los Cascarones, Abrigos de Andragulla, Abrigo del Mojao, Abrigo de los Gavilanes, Cueva de la Calesica y Cantos de Visera.

Una variación a este tipo general la vemos en la Cueva de los Cascarones. En ella, uno de los cruciformes representados muestra un doble trazo horizontal, como si de una duplicidad de miembros se tratase (fig. 2, núm. 1).

Tipo golondrina: derivado del tipo anterior, las diferencias básicas respecto a aquel son que el trazo vertical que simula el cuerpo no se desa- 
La pintura rupestre esquemática en Murcia. Estado de la cuestión

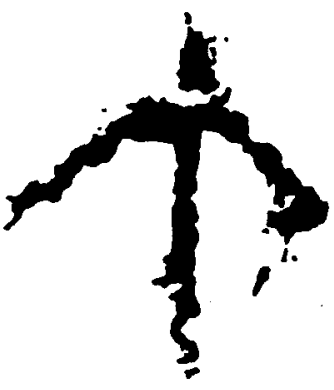

1

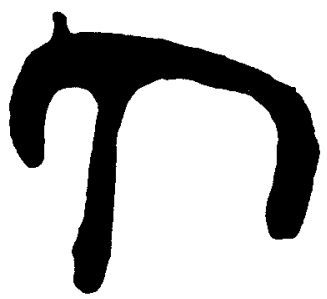

3

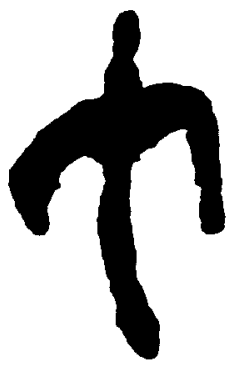

2

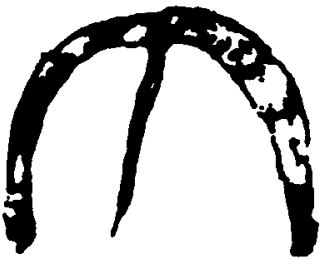

5

4

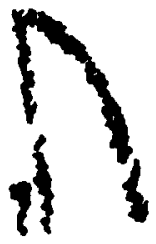

Figura 3. Tipos golondrina y ancoriforme: 1-2. Cañaica del Calar (Mateo, 1995; Beltrán, 1972); 3. Abrigo del Pozo (San Nicolás, 1985); 4. Abrigo de Mojao; 5. Abrigo del Milano (Alonso et alii, 1987).

rrolla por encima de lo que serian los hombros, configurando así una figura acéfala, y que la línea horizontal que representa a éstos aparece ligeramente arqueada (fig. 3, núms. 1-2). Sólo se encuentra en Cañaica del Calar. En realidad, no parece que se trate sino de una variación del tipo cruciforme.

Tipo ancoriforme: en este tipo, la figura queda reducida a un trazo horizontal ligeramente curvado, en el que a veces se señala otro pequeño trazo vertical que parece marcar el arranque del cuerpo. No se pinta la cabeza (fig. 3, núms. 3-5).

Lo registramos en los Abrigos de Andragulla, Abrigos del Pozo, Abrigo del Milano, Abrigo del Mojao, Cueva del Peliciego y Abrigo del Mediodía.

Tipo salamandra: esta figura, caracterizada por la duplicidad de miembros superiores, la encontramos en los Abrigos del Pozo, Cueva de la Serreta y Cantos de Visera.

185 


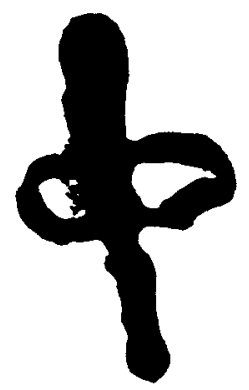

1

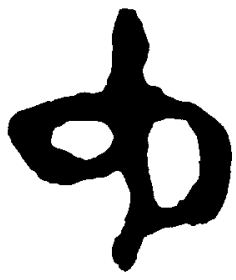

4

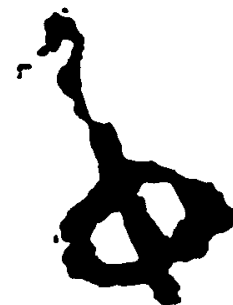

2

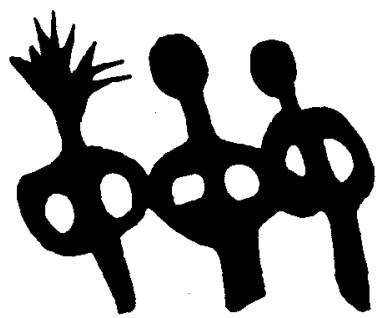

5

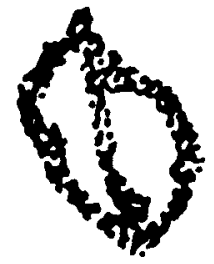

3

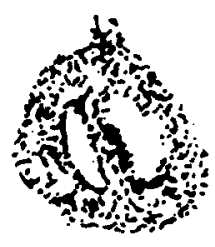

6

Figura 4. Tipo de brazos en asa: 1. Abrigo del Pozo (San Nicolás, 1985); 2. Cueva de la Serreta (Mateo, 1992). 3. Abrigos de las Enredaderas (Salmerón, 1987); 4-5. Abrigos de los Grajos (Beltrán, 1969); 6. Cueva del Peliciego (Fortea, 1974).

Tipo en " $X-Y$ ": definidas como representaciones humanas acéfalas cuyos miembros superiores aparecen abiertos, se localizan en los Abrigos del Cejo Cortado, Abrigo del Mojao, Abrigo de los Gavilanes, Abrigo de los Paradores y Abrigo del Mediodía.

Tipo "barra": aceptadas como figuraciones humanas sometidas a un alto grado de abstracción, éstas se reconocen en la Cueva de los Cascarones, Abrigo de la Fuente Serrano, Abrigos de Andragulla, Abrigo de Hondares, Abrigos del Pozo, Abrigos del Cejo Cortado, Abrigo del Mojao y Abrigo de los Gavilanes.

Se representan aisladas o formando grupos, siendo el único motivo pintado en el conjunto, como sucede en el Abrigo de la Fuente Serrano, 0 asociadas a otras figuras, como los cuadrúpedos y humanos de brazos en asa del Abrigo del Pozo.

Tipo «brazos en asa»: es de los motivos más representados, repitiéndose siempre el mismo esquema, un círculo atravesado por un trazo 


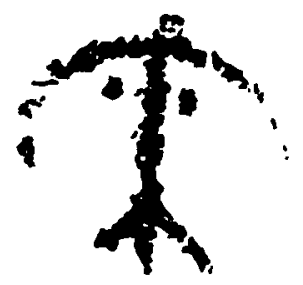

1

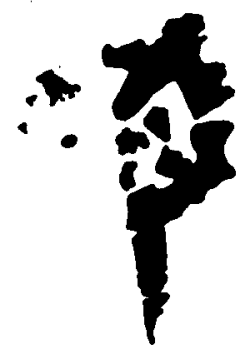

2

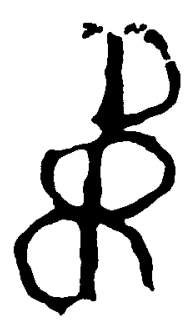

3

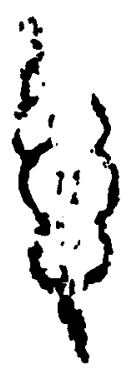

4

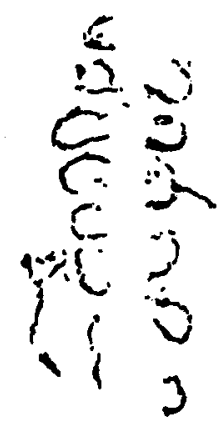

5

Figura 5. Ídolos: 1. Abrigo de los Gavilanes; 2. Abrigos de las Enredaderas (Salmerón, 1987); 3-4. Cueva de la Serreta (Mateo, 1992); 5. Abrigo del Milano (Alonso et alii, 1987).

vertical de longitud variable (fig. 4). Lo observamos en Cañaica del Calar, Abrigos del Pozo, Abrigo del Milano, Cueva de la Serreta, Abrigos de las Enredaderas, Barranco de los Grajos, Cueva del Peliciego, Cantos de Visera y Abrigo del Mediodía.

ÍDOLOS: este grupo, denominado así por el paralelismo que se puede establecer entre los ideogramas que lo integran con algunos objetos de la cultura material, engloba en realidad a varios tipos de figuras cuya interrelación, en verdad, no está del todo clara.

Oculados: sólo se documentan en el Abrigo de los Gavilanes y Abrigos de las Enredaderas (fig. 5, núms. 1-2).

Polilobulados: estas representaciones están formadas por un desarrollo vertical de dos o más elementos circulares (fig. 5, núms. 3-5). De compleja lectura, aunque en la mayoría de los casos se propongan con una significación humana, se localizan en el Abrigo del Milano, Cueva de la Serreta y Abrigos del Buen Aire. 

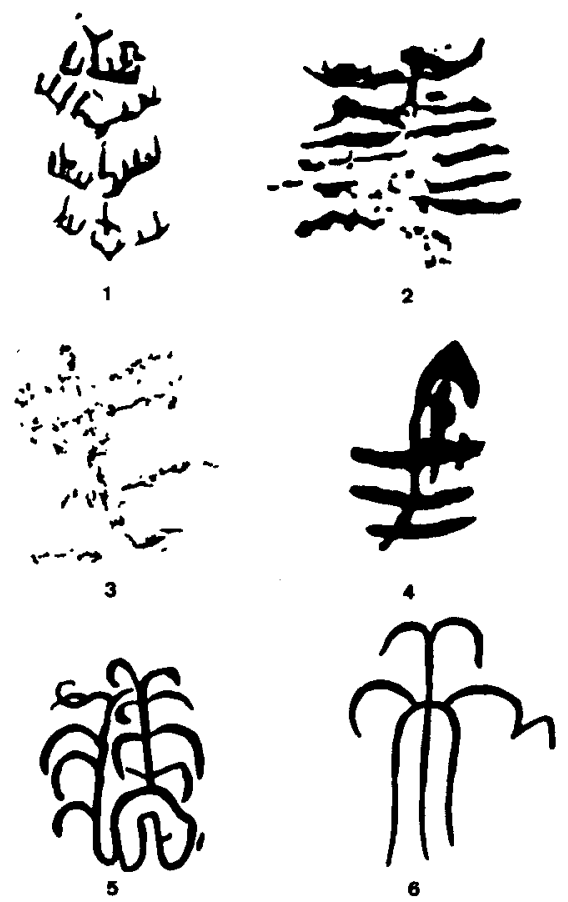

Figura 6. Ramiformes: 1. Abrigo de las Enredaderas (Salmerón, 1987); 2. Abrigo de los Gavilanes; 3. Abrigo de Hondares; 4. Abrigos de los Grajos (Beltrán, 1969); 5-6. Abrigo del Mediodia (Cabré, 1915).

RAMIFORMES: sujetos a interpretaciones diversas, como representaciones humanas, de elementos vegetales e incluso, según los casos como motivos zoomorfos, el esquema general que se repite en todos ellos es el de una línea vertical atravesada por múltiples trazos horizontales. La posición de estos últimos sirvió para establecer varios subtipos ${ }^{14}$. El denominado «arborescente" sólo lo encontramos en los Abrigos de las Enredaderas (fig. 6, núm. 1), mientras que el tipo "abeto" lo vemos en el Abrigo de Hondares, Abrigos del Pozo, Abrigo de los Gavilanes, Barranco de los Grajos y Abrigo del Mediodía (fig. 6, núms. 2-6).

Analizando este grupo de representaciones humanas en conjunto y considerando una serie de variables como son el número de veces que se ha representado cada uno de los tipos, las asociaciones que se dan entre ellos, re-

14 Acosta Martinez, P. (1983): «Técnica, estilo, temática y tipología en la pintura rupestre esquemática hispana", Zéphyrus, 36. Salamanca 1983, págs. 13-25. Pág. 23. 


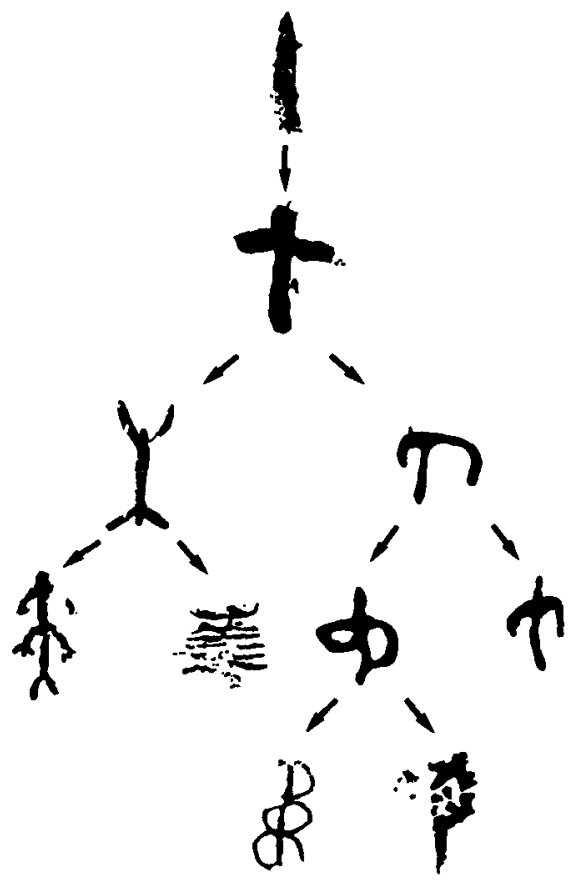

Figura 7. Hipótesis de evolución estilística de las abstracciones humanas en los conjuntos de Murcia.

cogidas en la tabla 1, su distribución en los conjuntos y paneles, y por último, una posible evolución estilística de sus formas, proponemos una especie de cuadro evolutivo de los distintos motivos antropomórficos representados en los conjuntos murcianos, que quedaria tal y como se refleja en la figura 7.

PUNTIFORMES: las representaciones de puntos, frecuentes en todo el espacio físico que abarca el fenómeno esquemático, suelen aparecer formando aglomeraciones, cuyo número varía desde unos pocos a formaciones de más de un centenar de ellos. Grupos de puntos los observamos en Cañaica del Calar, Abrigos de Andragulla, Abrigos del Pozo y Abrigos del Buen Aire.

Con carácter excepcional, en el Abrigo de los Gavilanes los motivos puntiformes aparecen aislados, mientras que en la Cueva del Esquilo se muestran alineados, formando un trazo de más de $1 \mathrm{~m}$ de longitud.

ZIG-ZAGS: los documentamos en los Abrigos del Pozo, Abrigos del Buen Aire, Cantos de Visera y Abrigo del Mediodía. 
ESTELIFORMES: localizados únicamente en Cañaica del Calar y Abrigos de las Enredaderas, en ambos casos se repite el mismo esquema de una forma circular radiada en su perímetro por trazos muy cortos.

TECTIFORMES: considerados como reflejo de construcciones o de posibles trampas de caza, entre otras acepciones, en realidad se trata de figuraciones de las que desconocemos su significado último. Dotados de una notable originalidad, podríamos identificar como tales a sendas figuras representadas en la Cueva de los Cascarones y Abrigos de Andragulla.

En el primer caso, se trata de una representación formada por líneas rectas dispuestas en forma de "diente de sierra", una de las cuales aprovecha un saliente del soporte rocoso a modo de cornisa para cerrar parcialmente la figura por su lado inferior. En el interior de uno de los triángulos descritos hay restos de pigmento que, por su estado de deterioro, no permiten identificar un motivo de tipologia clara ${ }^{15}$.

Por su parte, la figura de los Abrigos de Andragulla muestra una forma rectangular, abierta en uno de sus lados menores, estando compartimentado el espacio interno por un trazo rectilíneo.

RETÍCULAS: presentes tan sólo en los Abrigos del Cejo Cortado, se trata de dos figuras con forma oval cuyo espacio interior esta cuadriculado por varios haces de líneas. No parece que debamos relacionarlas con los motivos conocidos como placas o estelas (lám. IV).

SERPENTIFORMES: en el Abrigo de la Fuente reconocemos dos representaciones compuestas por varios trazos serpenteantes, de desarrollo vertical, que se unen en la parte superior en un mismo punto de origen (lám. II).

ZOOMORFOS: aunque se trata de uno de los temas más ampliamente repetido en el arte esquemático, en Murcia son escasos los zoomorfos que documentamos, observándose además una concentración de los mismos en unos pocos conjuntos.

Representaciones de cérvidos los hallamos en Cañaica del Calar, Abrigos del Cejo Cortado, Cueva de la Serreta, Cantos de Visera y Abrigos del Buen Aire (lám. V). Un cáprido se ha representado en el Abrigo de Canto Blanco, y no es posible determinar la especie por falta de detalles anatómicos en los cuadrúpedos de los Abrigos de la Risca, Abrigos del Pozo, Abrigos de las Enredaderas y Abrigo del Mediodía. Pág. 11.

15 Mateo Saura, M.A.-Bernal Monreal, J.A. Los conjuntos pintados... Op. cit. en la nota 6. 
En 1968, P. Acosta ${ }^{16}$ incluyó en su trabajo sobre el arte esquemático dos figuras de aves representadas en el conjunto yeclano de Cantos de Visera. Sin embargo, su posición infrapuesta a los motivos naturalistas levantinos, propios de varias fases de representación en el conjunto, y su lejanía formal respecto del resto de esquemas del panel nos lleva a dudar de esa filiación esquemática.

Quedan fuera de esta clasificación algunas figuras caracterizadas por una acusada originalidad que impide adscribirlas a alguno de los tipos propuestos. Es el caso de un motivo en forma de trazo horizontal y aspecto serpenteante, que sobrepasa los $180 \mathrm{~cm}$ de longitud, en el Abrigo de Hondares, de un signo en forma de " $V$ " de los Abrigos del Buen Aire, de unos trazos verticales, muy distantes en la forma a las barras, en la Cueva de los Pucheros o de una representación en forma de media luna, de destacables dimensiones, en la Cueva de la Plata de Totana.

ESCENOGRAFÍA: aún cuando en el arte esquemático parece haber una tendencia a la representación aislada de los motivos, cada uno de los cuales va cargado con un acusado simbolismo que lógicamente se nos escapa, siendo la única relación que hay entre ellos muchas veces la de compartir un mismo espacio de representación, en ocasiones encontramos reflejados en las pinturas testimonios etnográficos y de actividades sociales o económicas. No obstante, digamos de entrada que en Murcia, aunque analizamos varias posibles composiciones, en ninguna de ellas es fácil determinar un significado claro.

En los Abrigos del Pozo se han representado en un mismo panel cuatro humanos de brazos en asa, tres cuadrúpedos de especie no identificable y cinco motivos en forma de barra (lám. VI). A partir de la lectura de las barras como azadas, estas figuras se consideraron reflejo de alguna actividad de tipo agropecuario ${ }^{17}$. Sin embargo, aunque esta interpretación nos parece un tanto aventurada, lo que sí debemos aceptar es una relación inequívoca entre todos los elementos implicados en la composición. El que no podamos definir la especie de los animales nos limita también a la hora de determinar si se pudiera tratar de una escena doméstica.

En los Abrigos del Cejo Cortado encontramos una asociación de cuatro figuras antropomorfas, quizá una de ellas femenina. Sin duda, guardan una relación entre sí, pero para nosotros es desconocida ya que no hay en esa composición los suficientes elementos que clarifiquen su significado.

\footnotetext{
16 Acosta Martínez, P. La pintura rupestre..., Op. cit. en la nota 2. Pág. 57.

17 SAN Nicolás DEL TORO, M. "Las pinturas rupestres esquemáticas...", Op. cit. en la nota 6. Pág. 114.
} 
Por su parte, en Cañaica del Calar se han representado en un mismo espacio tres aglomeraciones de puntos, varios ciervos, un soliforme y dos humanos. Parece claro que todos estos elementos mantienen algún tipo de relación, máxime si tenemos en cuenta que uno de los antropomorfos se encuentra entre dos de los grupos de puntos y el otro junto a los cuadrúpedos. Si consideramos la especie salvaje de los animales y aceptamos como posible arma el objeto que porta el antropomorfo de la parte inferior del friso, podriamos estar ante una escena de carácter cinegético (lám. VII).

Por lo que se refiere a detalles de tipo etnográfico, se aprecia una pobreza en este campo en las estaciones murcianas. Al margen de la ya comentada figura humana de la Cueva de la Serreta, tan sólo podemos reseñar la presencia de lo que podrían ser penachos de plumas o, tal vez simples peinados, en dos figuras de Cantos de Visera, una cruciforme (fig. 2, núm. 5) y la otra de brazos en asa, y en otro humano de brazos en asa del Barranco de los Grajos (fig. 4, núm. 5).

La presencia de dos puntos pegados al cuerpo en una figura antropomorfa del Abrigo de los Gavilanes puede llevarnos a interpretarlos como posibles elementos de adorno (lám. III).

En el grupo de las armas y objetos habria que incluir dos pictogramas en forma de media luna del Abrigo del Mediodía, próximos en la forma al tipo llamado «boomerang" de P. Acosta ${ }^{18}$, y el objeto alargado del antropomorfo de Cañaica del Calar.

Por su parte, la proximidad de un cuadrúpedo a uno de los signos reticulares en los Abrigos del Cejo Cortado podría llevarnos a interpretario como una red o trampa de caza (lám. IV).

En la escasez de este tipo de figuraciones influye, sin duda, el que la mayor parte de la pintura esquemática regional tenga una caracterización simbólica, con un marcado predominio de las abstracciones humanas y las figuras aisladas, en detrimento de las agrupaciones compositivas.

Muy importante por las implicaciones cronólogicas que conlleva se nos presenta la representación de un posible jinete en el Abrigo del Mediodía de Yecla. Aunque un tanto confusa por el acusado esquematismo que presenta, $H$. Breuil y $M$. Burkitt ${ }^{19}$ no sólo la aceptaron como tal, sino que además propusieron la existencia de una segunda figura de caballero al inter-

18 acosta Martínez, P. La pintura rupestre..., Op. cit. en la nota 2. Pág. 109.

19 BREUIL, H.-BuRKITT, M. "Les peintures rupestres...", Op. cit. en la nota 3. 
pretar como tal uno de los motivos situados a su derecha. Si bien podríamos aceptar, con ciertas reservas, la situada en la parte izquierda del friso, no compartimos la identificación de esa segunda figura, que incluímos en el grupo de los ramiformes (lám. Vili).

\section{ASPECTOS CRONOLÓGICOS}

Es el apartado cronológico uno de los principales caballos de batalla en los estudios de arte rupestre en general, agravado cuando nos referimos a lo que conocemos como Arte Esquemático, ya que bajo este epigrafe genérico se engloban diversos horizontes iconográficos, en ocasiones muy dispares y sin relación alguna, cuya único rasgo común es el de compartir el esquema y la abstracción como forma gráfica de expresión de un contenido, muy probablemente con una intención religiosa.

En esa especie de cajón de sastre en que se puede convertir el Arte Esquemático englobamos las manifestaciones pintadas parietales, no ajenas a particularidades regionales y en estrecha relación con el substrato cultural de cada zona, pero también al llamado arte megalítico, con evidentes relaciones con aquella, y el horizonte de las insculturas y petroglifos, que conforman un ciclo artístico con personalidad propia y al margen del otro esquematismo de la pintura o el grabado.

Centrándonos en la pintura esquemática, hemos de admitirla como una realidad muy compleja, con unos límites cronológicos amplios y que, con adaptaciones, pervive en diferentes contextos culturales. Hay motivos que, como los denominados ídolos, parecen tener un desarrollo más acusado en una etapa concreta, pero otros se muestran, con o sin variaciones tipológicas, desde los orígenes de la pintura esquemática hasta sus momentos finales.

Sucede, por ejemplo, con los motivos conocidos como ramiformes, que encontramos en un Neolítico final en vasijas cerámicas de la Carigüela de Piñar (Granada), asociados a niveles calcolíticos en Millares (Almería), a campaniforme en el Cerro de la Virgen (Granada) y en un horizonte de transición del Eneolítico al Bronce I en el Castillajero de los Moros (Valencia) ${ }^{20}$.

20 Acosta Martínez, P. “El arte esquemático ibérico: problemas de cronología preliminares", Scripta Praehistorica. F. Jordá Oblata Salmanticae, Salamanca 1982, págs. 31-61. 
Varios son los puntos de referencia con los que contamos a la hora de perfilar una cronología para las manifestaciones pintadas en cuevas y abrigos. De un lado, la propia información que las pinturas contienen referentes a detalles socioeconómicos y etnográficos propios de la sociedad creadora del arte. No obstante, cuando nos referimos al arte esquemático y dada la identidad de la mayor parte de sus representaciones, la lectura etnográfica que podemos efectuar a partir de lo representado es muy limitada.

Un segundo elemento cronológico puede ser el contexto arqueológico que rodea a cada conjunto, pero este debe ser utilizado con prudencia puesto que es arriesgado correlacionar de forma generalizada un grupo de pinturas con los yacimientos que hay en su entorno, sobre todo si esos yacimientos no han reportado argumentos reales que muestren una dependencia.

En estos últimos años, la relación entre arte rupestre y cultura material se ha revelado como uno de los instrumentos de aproximación cronólogica más interesantes. Hace tiempo que una vinculación de la cultura material con el arte permitió establecer un origen para la pintura esquemática en un Neolítico antiguo-medio ${ }^{21}$, lo que vino a trastocar un tanto las ideas, hasta ese momento muy consolidadas, de que el esquematismo era fruto de importaciones foráneas traídas por los metalúrgicos orientales. Al mismo tiempo, estos nuevos datos permitieron ir dando al substrato indígena un papel más activo en la formación y desarrollo del esquematismo que, indudablemente, era receptor de otras ideas como pudieron ser en un momento concreto de su desarrollo las de esos prospectores de metal procedentes del Mediterráneo oriental, pero que eran transformadas y adaptadas al código esquemático ya existente.

Por el momento, en Murcia, el estudio de la cultura material desde la etapa más antigua neolítica y su relación con la pintura esquemática parece indicar un desarrollo más acusado de la misma a partir de fechas eneolíticas, en las que empezamos a encontrar relaciones entre pintura y arte mueble, si bien, como veremos, hay datos que llevan el posible origen de la pintura esquemática a fechas más antiguas, neolíticas.

${ }_{21}$ De entre los diversos trabajos en los que se ha buscado un acercamiento entre arte rupestre y cultura material hemos de destacar ACOSTA MARTínEZ, P. "El arte esquemático ibérico...", Op. cit. en la nota 17. CaraAsco, J. et alii, "Las pinturas rupestres del Cerro del Piorno (Pinos Puente, Granada). Consideraciones sobre el arte rupestre esquemático de las sierras subbéticas andaluzas", Cuadernos de Prehistoria de la Universidad de Granada, 7. Granada 1982, págs. 113-169. Marcos Pous, A. "Sobre el origen neolítico del arte esquemático penínsular", Corduba Archaeologica, 9, Córdoba 1981, págs. 63-71. Martl Oliver, B. y Hernández Pérez, M.S. El Neolitic valenciá: art rupestre i cultura material. Valencia 1988. 
Paralelos cerámicos de etapa eneolítica con algunos motivos pintados los documentamos en varios yacimientos ${ }^{22}$. Motivos soliformes encontramos incisos en un vaso ovoide de Las Casicas de Caravaca y en un fragmento cerámico hallado en la Cueva de la Hoja de Cehegín. Otro soliforme, esta vez pintado, se documenta en el interior de una vasija de la Cueva de las Palomas, también en Cehegín.

Por su parte, una decoración pintada a base de zig-zags y triángulos, paralelizable a algunos zig-zags del arte esquemático, la vemos en un vaso de la Cueva de los Tiestos de Jumilla, mientras que, algo más alejados formalmente, podemos reseñar también los haces de líneas ondulantes, de color rojo, de un vaso de alabastro de los Blanquizares de Lebor, en Totana.

Mucho más rico en testimonios materiales y dentro del mismo contexto cronológico eneolítico-calcolítico se nos muestra el grupo de los ídolos y amuletos, fabricados en hueso o piedra ${ }^{23}$. Oculados sobre hueso se han hallado en Los Royos de Caravaca y en el Cabezo del Oro de Bullas, y cruciformes, elaborados en el mismo soporte, se han encontrado en El Capitán de Lorca. Otros se han realizado en caliza, siendo plaquitas ovaladas de dimensiones reducidas, apenas $2-3 \mathrm{~cm}$, y con una decoración pintada en ocre. Con una escotadura en su tercio superior, estos ídolos conocidos como «tipo Represa", se han interpretado como esquematizaciones humanas. Junto a éstos, formaciones naturales de piedra, denominados ídolos atipo Camarillas", se han encontrado en numerosos contextos de habitación, como

22 Sobre el material cerámico, Arribas, A. «El ajuar de las cuevas sepulcrales de los Blanquizares de Lebor (Murcia)", Memorias del Museo Arqueológico Provincial, 1952-1953, XIIIXIV, Madrid 1956, págs. 78-126. LomBA MAURANDI, J. “La cerámica pintada del Eneolítico en la región de Murcia», Anales de Prehistoria y Arqueología, 7-8, Universidad de Murcia, Murcia 1992 , págs. 35-46. Molina Grande, M.C. "La Cueva de los Tiestos (Jumilla, Murcia). La cerámica pintada", Homenaje a Jerónimo Molina, Murcia 1990, págs. 51-72. Motos, F. de, "La Edad Neolítica en Vélez-Blanco", Memorias de la Comisión de Investigaciones Paleontológicas y Prehistoricas, 19. Madrid 1918. MuÑoz AMLlıIA, A.M. "Lineas generales de la Prehistoria", Historia de Cartagena, vol. II, Murcia 1986, págs. 19-31. SAN NICOLAS DEL TORO, M. "Un vaso cerámico con motivo solar de Caravaca (Murcia)", Anales de la Universidad de Murcia, Facultad de Letras, XLll, Murcia 1984, págs. 49-55. San Nicolás DEL TORO, M. "Materiales arqueológicos de las Cueva de la Peña Rubia", Caesaraugusta, 64, Zaragoza 1987, págs. 87-108.

${ }^{23}$ Sobre los ídolos, Ayala JuAn, M.M. "El ídolo de Caravaca de la Cruz", Pyrenae. Barcelona 1981, págs. 361-363. AYALA JuAN, M.M. "Los ídolos cruciformes del poblado del Capitán (Lorca)", Anales de la Universidad de Murcia, Facultad de Letras, XLIII, núm(s) 3-4, Murcia 1984. AyALA JUAN, M.M. "Contribución al estudio de los ídolos oculados del Sureste español», El Eneolítico en el País Valenciano, Alcoy 1986, págs. 151-166. IDAÑEz SANCHEZ, J.F. "Avance al estudio de la necrópolis eneolitica de Murviedro", XVII Congreso Nacional de Arqueología. Zaragoza 1985, págs. 197-209. SAN NICOLÁS DEL TORO, M. "Un nuevo idolo del Bronce I procedente de la cueva sepulcral de La Represa, Caravaca (Murcia)", Revista Argos, 2, Caravaca 1982, págs. 21-50. SAN NICOLÁS DEL TORO, M. “Aproximación al conocimiento de los Idolos Tipo Pastora: los oculados en Murcia", El Eneolítico en el País Valenciano, Alcoy 1986, págs. 165-174. 
El Prado en Jumilla, Las Marirías en Cieza o Los Molinicos en Moratalla, y nos recuerdan mucho a los motivos polilobulados del arte esquemático.

Otros ídolos zoomórficos se documentan en Murviedro (Lorca) y Cueva de las Palomas (Cehegín). En el primero, se trata de tres amuletos sobre hueso, dos de ellos de roedores y el tercero de un posible suido, mientras que los hallados en Cehegín son figuras de lagomorfo en actitud estática, con una perforación vertical, lo que indica que eran para llevar colgados.

En este estado de cosas, cuando la mayor parte de elementos de la cultura material relacionable con las pinturas rupestres parece apuntar hacia el Eneolítico-Calcolítico como el momento de máximo desarrollo del arte rupestre esquemático en Murcia, cobra especial importancia el hallazgo de restos de pigmento mezclados con el sedimento en el estrato VI de los Abrigos del Pozo ${ }^{24}$. Con una fecha absoluta de $6260 \pm 120$ B.P., se corresponde con un Neolítico antiguo, quizás medio, al que habría que adscribir las pinturas existentes en ese abrigo. De confirmarse este dato, los motivos más antiguos del código esquemático en Murcia podrian ser las barras, los humanos de brazos en asa y los cuadrúpedos.

En la Cueva de la Serreta de Cieza también aparecieron restos de colorante en un nivel neolítico ${ }^{25}$. No obstante, el que en este conjunto haya representaciones naturalistas junto a las esquemáticas nos limita un tanto a la hora de relacionar ese hallazgo con uno u otro horizonte artístico, si bien en nuestros estudios sobre estas pinturas hemos defendido la tesis de que en este yacimiento se produce una coexistencia de la tradición naturalista levantina, propia de una economía predadora, con la nueva corriente esquemática, vinculada ya a un nuevo sistema económico productor ${ }^{26}$.

Para los momentos finales de la pintura esquemática es importante la aceptación de la figura de un jinete en el Abrigo del Mediodía de Yecla, puesto que ello nos llevaría a fechas muy recientes. La utilización del caballo como animal de monta no se documenta hasta el Bronce final, si nos atenemos a registros arqueológicos como los restos de bocados hallados, por ejemplo, en el poblado almeriense de Fuente Alamo ${ }^{27}$. Ello supondría llevar estas pinturas rupestres hasta finales del $11^{\circ}$ milenio a. $\mathrm{C}$.

24 Martinez Sanchez, C. "Nueva datación de C-14 para el Neolítico de Murcia: los Abrigos del Pozo (Calasparra)», Trabajos de Prehistoria, 51-1. Madrid 1994, págs. 157-161.

25 Salmerón Juan, J. "Cueva-sima de la Serreta (Cieza)", V Jornadas de Arqueología Regional, 1994. Murcia 1994, pág. 8.

${ }_{26}$ Mateo Saura, "Las pinturas rupestres de La Serreta...", Op. cit. en la nota 6.

27 Schubart, H.-ARTEAGa, O. «Fundamentos arqueológicos para el estudio socio-económico y cultural del área de El Argar", Homenaje a L. Siret. Cuevas de Almanzora, 1984. Sevilla 1986, págs. 289-307. 


\section{TABLA 1}

Asociaciones humanos-abstracciones humanas.

\begin{tabular}{|l|c|c|c|c|c|c|c|c|c|c|c|}
\hline TIPOS & 1 & 2 & 3 & 4 & 5 & 6 & 7 & 8 & 9 & 10 & 11 \\
\hline 1. Antropomorfos & & $\mathrm{X}$ & $\mathrm{X}$ & & $\mathrm{X}$ & & $\mathrm{X}$ & $\mathrm{X}$ & & & $\mathrm{X}$ \\
\hline 2. Brazos en Asa & $\mathrm{X}$ & & $\mathrm{X}$ & & $\mathrm{X}$ & $\mathrm{X}$ & & $\mathrm{X}$ & $\mathrm{X}$ & $\mathrm{X}$ & $\mathrm{X}$ \\
\hline 3. Cruciformes & $\mathrm{X}$ & $\mathrm{X}$ & & & $\mathrm{X}$ & & $\mathrm{X}$ & $\mathrm{X}$ & & & $\mathrm{X}$ \\
\hline 4. Golondrina & $\mathrm{X}$ & $\mathrm{X}$ & & & & & & & & & \\
\hline 5. Ancoriformes & $\mathrm{X}$ & $\mathrm{X}$ & $\mathrm{X}$ & & & $\mathrm{X}$ & $\mathrm{X}$ & $\mathrm{X}$ & & $\mathrm{X}$ & $\mathrm{X}$ \\
\hline 6. Salamandra & $\mathrm{X}$ & $\mathrm{X}$ & & & $\mathrm{X}$ & & & $\mathrm{X}$ & & $\mathrm{X}$ & $\mathrm{X}$ \\
\hline 7. Tipos X-Y & $\mathrm{X}$ & $\mathrm{X}$ & $\mathrm{X}$ & & $\mathrm{X}$ & & & $\mathrm{X}$ & & & $\mathrm{X}$ \\
\hline 8. Barras & $\mathrm{X}$ & $\mathrm{X}$ & $\mathrm{X}$ & & $\mathrm{X}$ & $\mathrm{X}$ & $\mathrm{X}$ & & & & $\mathrm{X}$ \\
\hline 9. Oculados & & $\mathrm{X}$ & & & & & & & & & $\mathrm{X}$ \\
\hline 10. Polilobulados & $\mathrm{X}$ & $\mathrm{X}$ & & & $\mathrm{X}$ & $\mathrm{X}$ & & & & & \\
\hline 11. Ramiformes & $\mathrm{X}$ & $\mathrm{X}$ & $\mathrm{X}$ & & $\mathrm{X}$ & & $\mathrm{X}$ & $\mathrm{X}$ & $\mathrm{X}$ & & \\
\hline
\end{tabular}

\section{ADDENDA}

Con posterioridad a la redacción de este trabajo hemos localizado en la Comarca del Noroeste dos nuevos yacimientos de estilo esquemático, los Abrigos de Zaén y los Abrigos de la Ventana, ambos en Moratalla. En Zaén documentamos una representación circuliforme y un posible motivo vegetal, mientras que en los Abrigos de la Ventana registramos más de una treintena de figuraciones cruciformes, con dos o más trazos orizontales. Estos conjuntos, por lo reciente de su descubrimiento, están en fase de estudio. Asimismo, se ha publicado también ahora una breve reseña sobre los Abrigos de Benizar, en Moratalla, en los que junto a representaciones naturalistas encontramos varios motivos esquemáticos, entre ellos, un soliforme, una figura circular, puntos y restos de lo que parecen ser barras (Alonso TEJADA, A. y GRIMAL, A. «Investigaciones sobre arte rupestre en Moratalla. II campaña", Memorias de Arqueología 1990. Murcia 1996, págs. 21-31). 


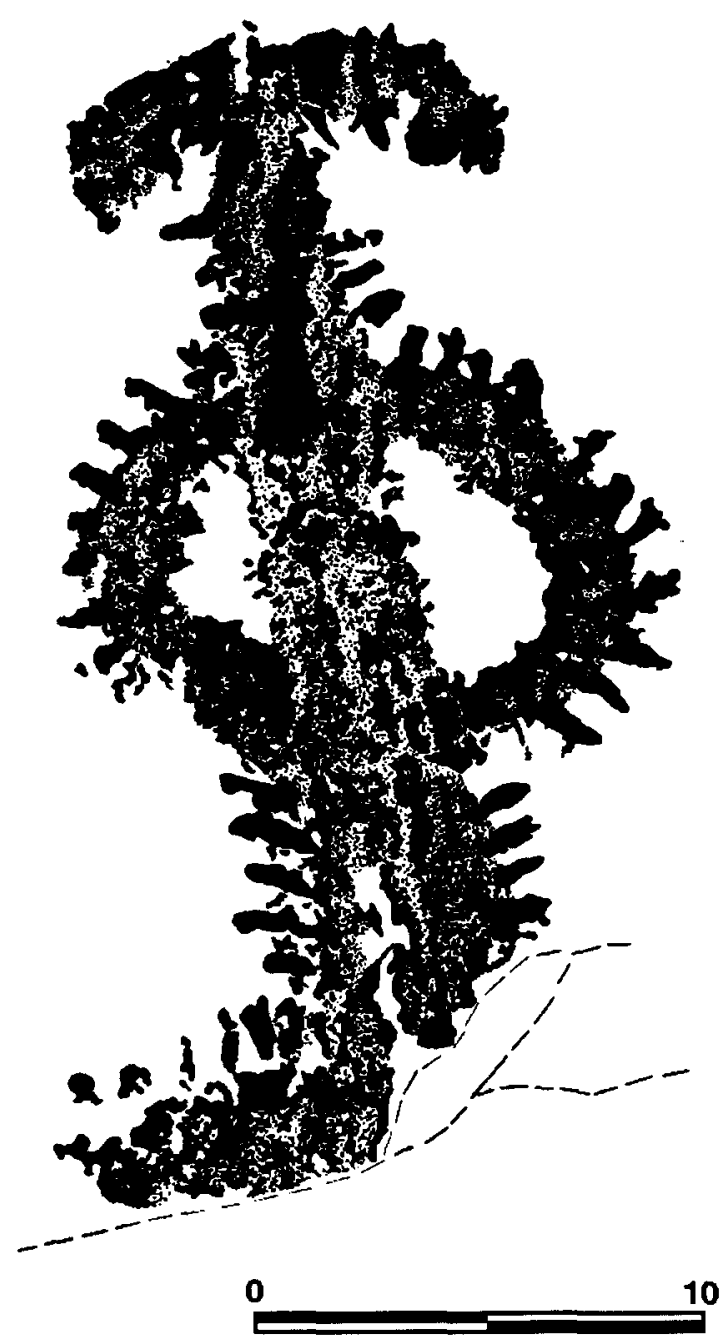

Lámina l: Esquema humano de brazos en asa de la Cueva de la Serreta (Cieza). (Calco de M.A. Mateo Saura). 

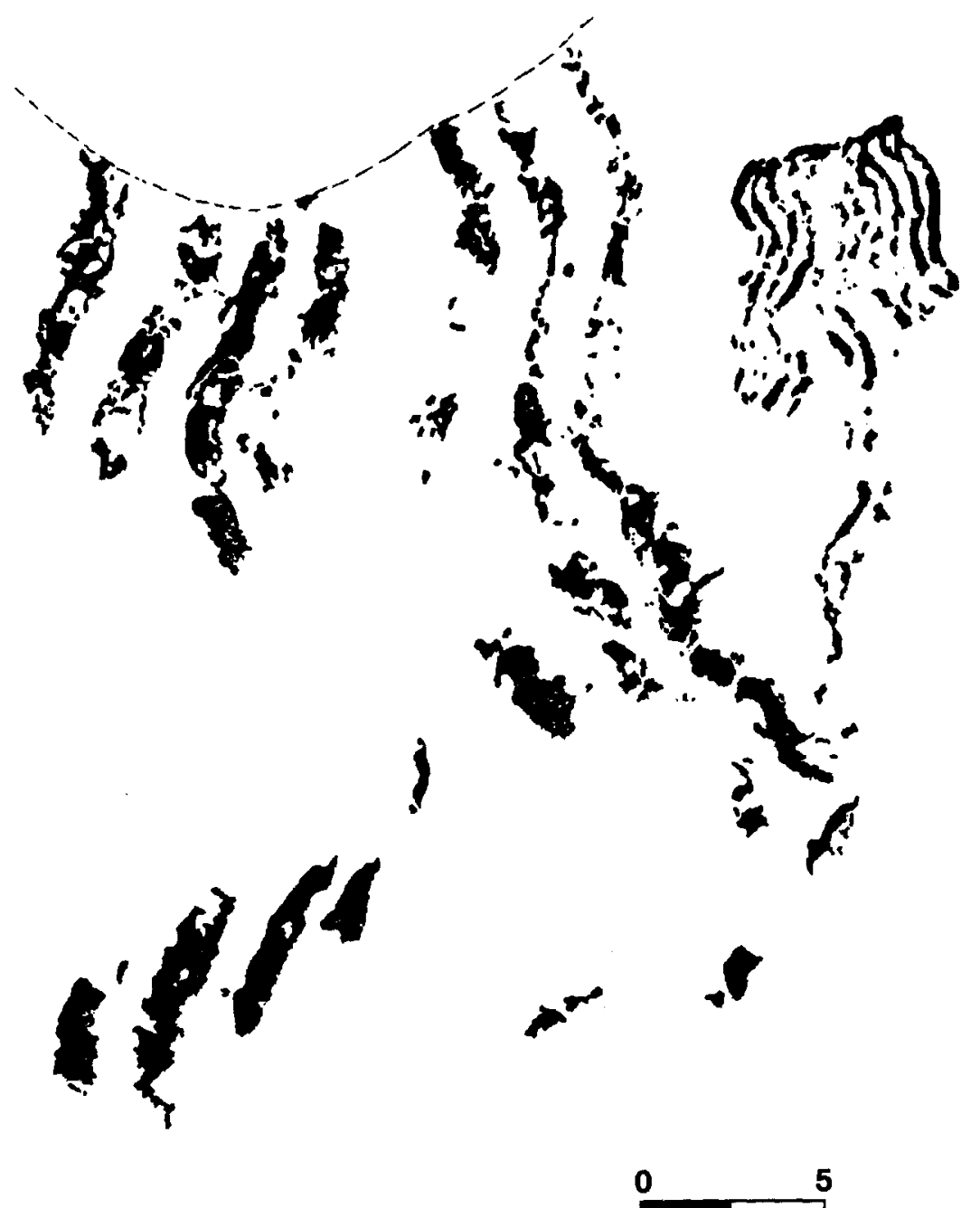

Lámina II: Serpentiformes en el Abrigo de la Fuente (Moratalla). (Calco de M.A. Mateo Saura). 


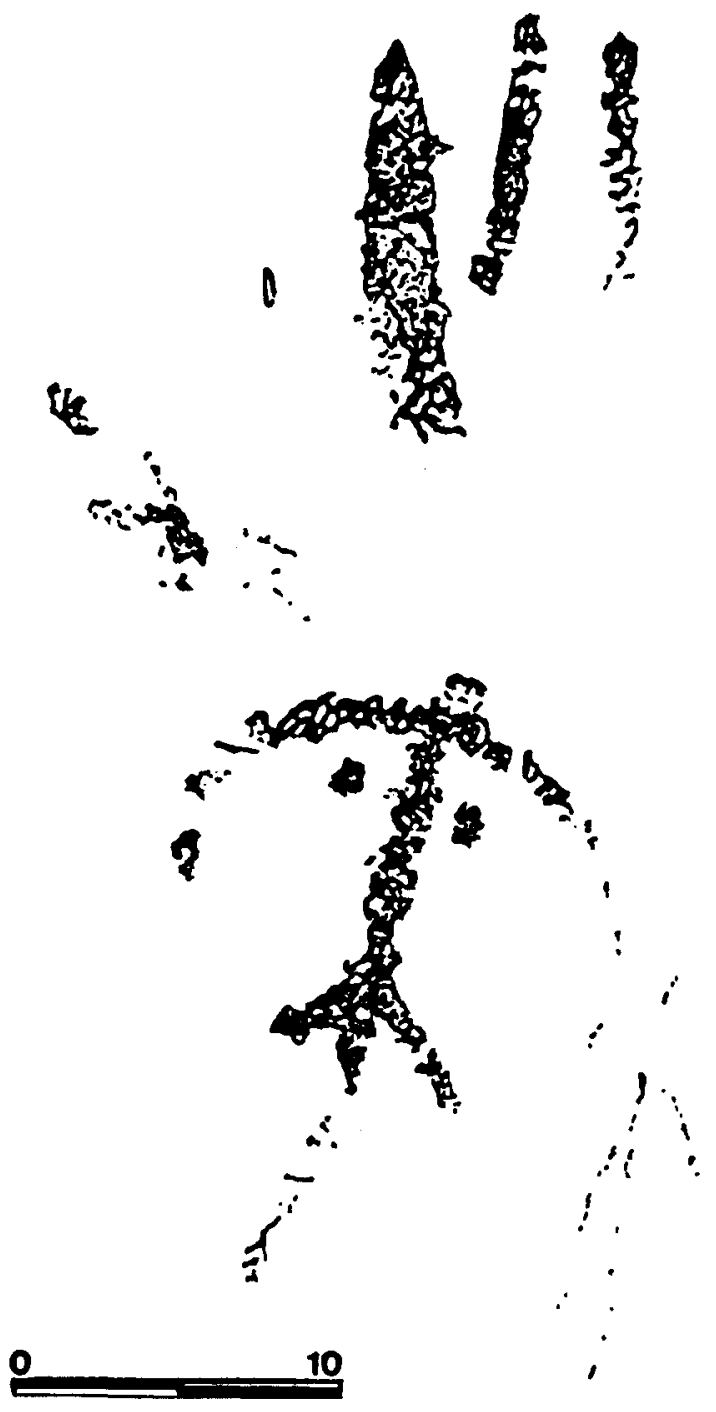

Lámina III: Esquema humano en el Abrigo de los Gavilanes (Lorca). Los puntos pueden darle una significación como oculado, o ser elementos de adorno personal. (Calco de M.A. Mateo Saura y A. Martínez). 

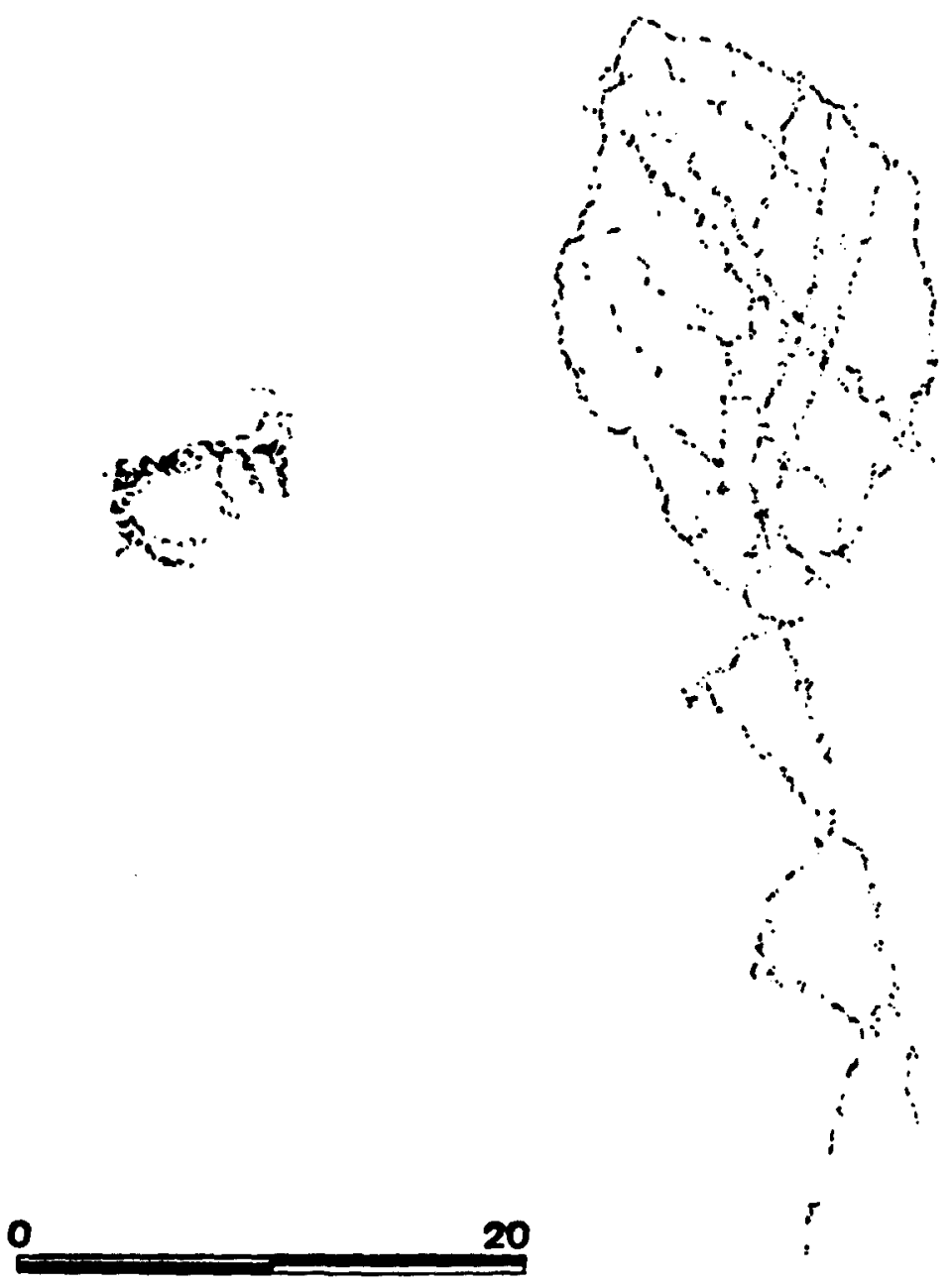

Lámina IV: Motivo reticular en los Abrigos del Cejo Cortado (Mula). (Calco de R. Montes). 


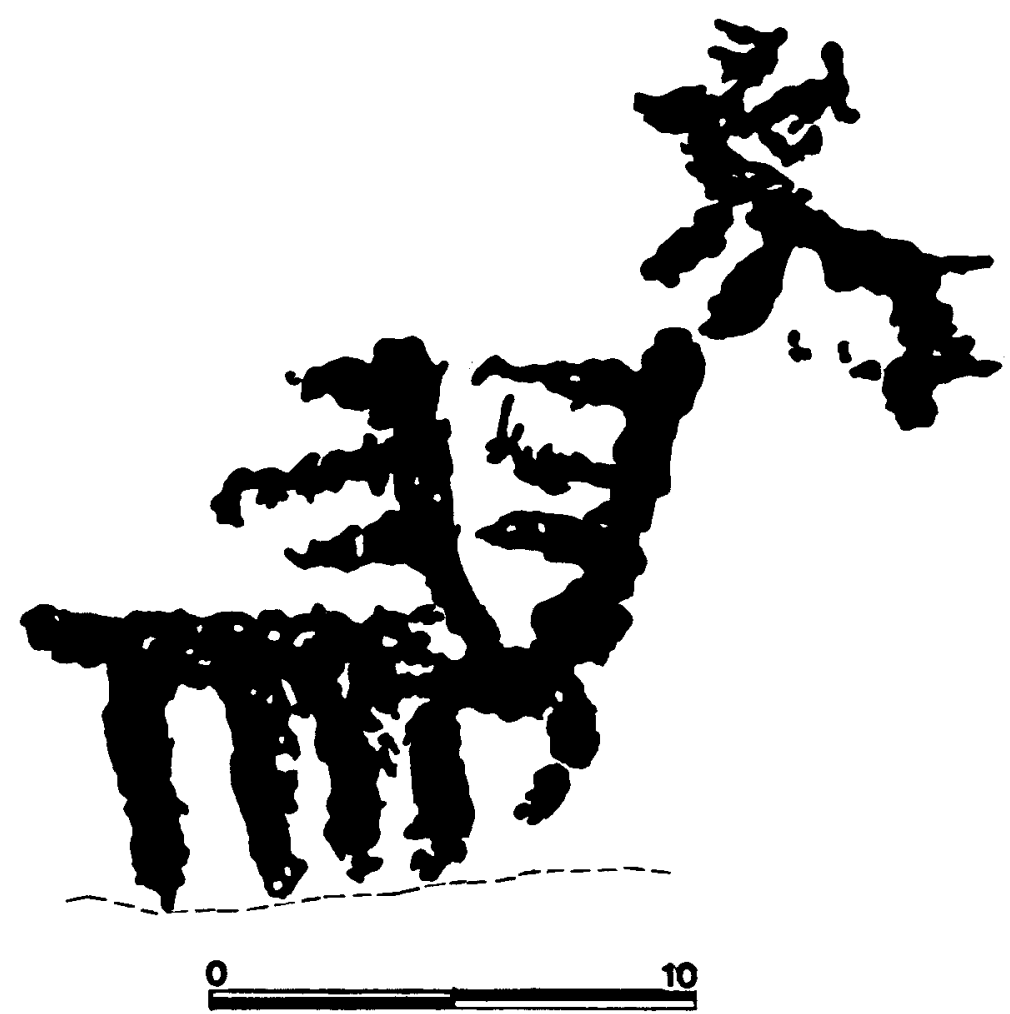

Lámina V: Figuras de cérvidos en los Abrigos del Buen Aire (Jumilla). (Calco de M.A. Mateo y M" I. Giménez). 

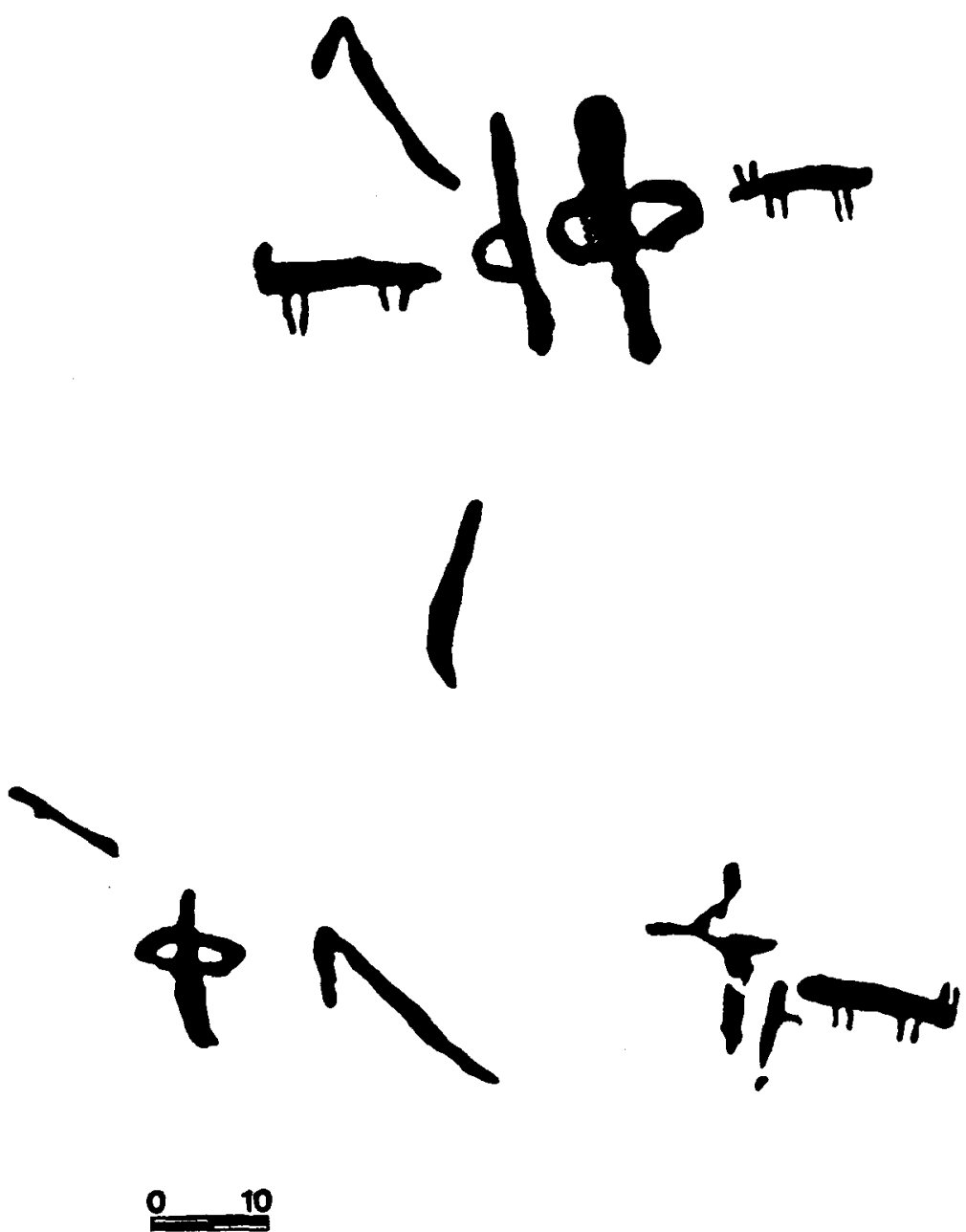

Lámina VI: Composición con cuadrúpedos, humanos en phi y barras en el Abrigo del Pozo (Calasparra). (Calco de M. San Nicolás). 

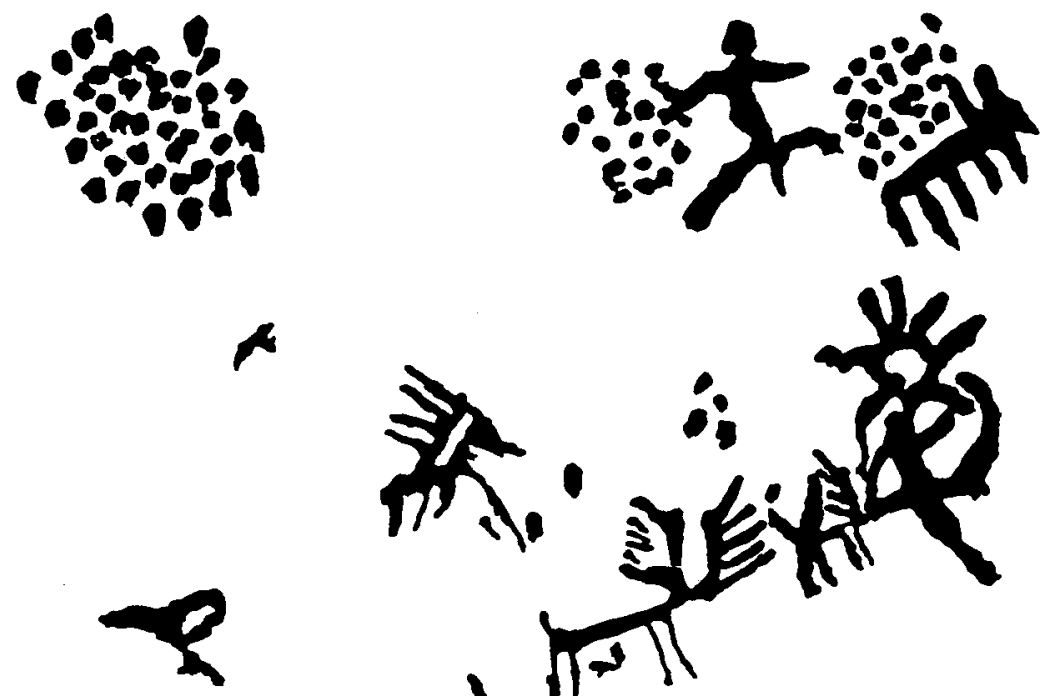

(3)
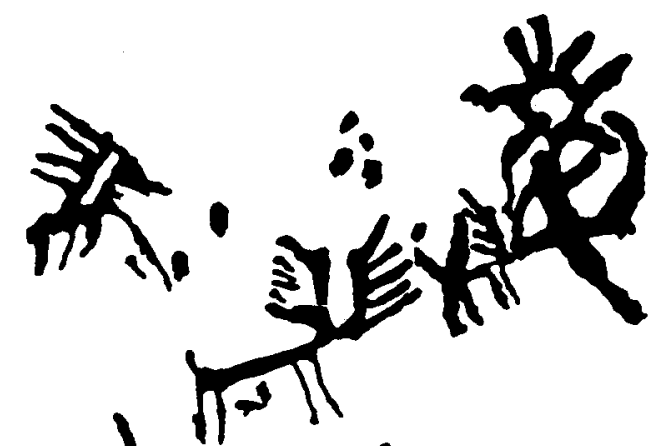

\section{o}

20

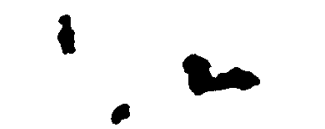

2.

ofa.

$\rightarrow P$

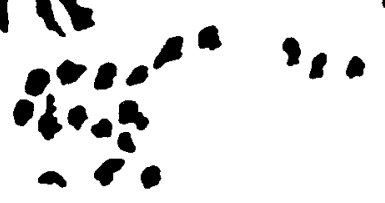

Lámina VII: Posible composición de significado cinegético en Cañaica del Calar (Moratalla). (Calco de J. Carbonell). 

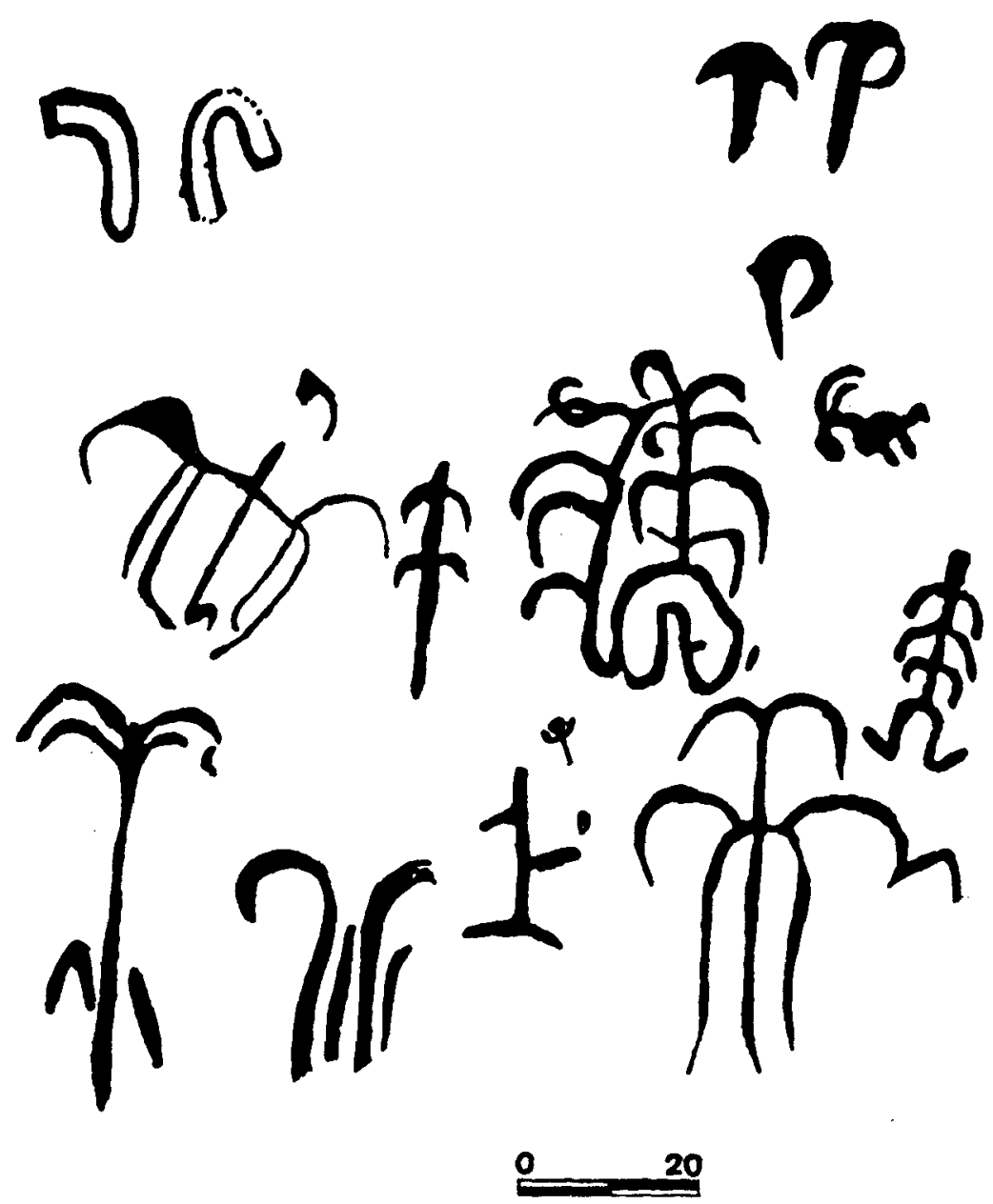

Lámina VIII: Grupo de ramiformes y, en la parte izquierda, posible representación de jinete en el Abrigo del Mediodía (Yecla).

(Calco de H. Bremil). 